\title{
Influence of water on yields and isotopic fractionations of gas hydrocarbons generated from oil cracking
}

\author{
Yongbin Jin, ${ }^{1,2,4}$ XiAnming XiaO, ${ }^{1 *}$ YongChun TANG,${ }^{3}$ HUi Tian ${ }^{1}$ and JinZHONG LiU ${ }^{1}$ \\ ${ }^{1}$ State Key Laboratory of Organic Geochemistry, Guangzhou Institute of Geochemistry, Chinese Academy of Sciences, \\ Guangzhou 510640, China \\ ${ }^{2}$ South China Sea Institute of Oceanology, Chinese Academy of Sciences, Guangzhou 510301, China \\ ${ }^{3}$ Power, Environmental, and Energy Research Center, California Institute of Technology, \\ 738 Arrow Grand Circle, Covina, California 91722 U.S.A. \\ ${ }^{4}$ Graduate School of Chinese Academy of Sciences, Beijing 100049, China
}

(Received June 22, 2008; Accepted January 21, 2009)

\begin{abstract}
Few investigations have been made to discuss the influence of water on the yields and carbon and hydrogen isotopic ratios of gas hydrocarbons generated from oil cracking although water occurs in oil reservoirs. In this study, a pyrolysis experiment for a crude oil under hydrous and anhydrous conditions in a gold tube confined system was performed at $T=$ $370^{\circ} \mathrm{C}, P=21 \mathrm{MPa}$ and times from 1 to 7 days. It is found that water has an obvious inhibition on the gas yields generated from oil cracking and a pronounced influence on the carbon and hydrogen isotopic fractionations of the cracking gas. Compared with the anhydrous pyrolysis, the hydrous pyrolysis has a smaller $\mathrm{C}_{1-5}$ alkane yields and lighter carbon and hydrogen isotopic ratios of the $\mathrm{C}_{1-3}$ hydrocarbons within maturity levels investigated. The differences in their $\mathrm{C}_{1-5}$ alkane yields reach $3-12 \mathrm{ml} / \mathrm{g}$, in their $\delta^{13} \mathrm{CH}_{4}, \delta^{13} \mathrm{C}_{2} \mathrm{H}_{6}$ and $\delta^{13} \mathrm{C}_{3} \mathrm{H}_{8}$ values reach $1.0-2.7 \%$, $0.2-0.8 \%$ and $0.2-0.3 \%$, respectively, and in their $\delta \mathrm{D}_{\mathrm{CH} 4}, \delta \mathrm{D}_{\mathrm{C} 2 \mathrm{H} 6}, \delta \mathrm{D}_{\mathrm{C} 3 \mathrm{H} 8}$ values reach 5-16\%o, 22-80\%o and 4-13\%o, respectively. Moreover, the hydrous pyrolysis experiment formed a greater amount of $\mathrm{H}_{2}$ and alkenes and a smaller amount of $\mathrm{CO}_{2}$ than the anhydrous pyrolysis experiment did. The differences of $\mathrm{H}_{2}$, ethene, propene and $\mathrm{CO}_{2}$ between the two experiment conditions are $0.44-2.12$ $\mathrm{ml} / \mathrm{g}, 0.03-0.05 \mathrm{ml} / \mathrm{g}, 0.20-0.34 \mathrm{ml} / \mathrm{g}$ and $0.08-0.98 \mathrm{ml} / \mathrm{g}$, respectively. These results indicate that these differences in carbon and hydrogen isotopic ratios of generated gases between the hydrous and anhydrous experiments is possibly because water affects the free radical reactions of oil cracking and inhibits the combination between alkyl and hydrogen to form alkane to some extent, rather than due to the isotopic exchange reactions between water and some pyrolysates as usually believed for kerogen hydrous pyrolysis.
\end{abstract}

Keywords: crude oil, pyrolysis experiment, water, gas yield, carbon and hydrogen isotope

\section{INTRODUCTION}

Numerous investigations based on laboratory pyrolysis experiments indicate water has an influence on products and processes in cracking of organic matters to oil and gas, such as kerogens, coals and source rocks (e.g., Hesp and Rigby, 1973; Price, 1993; Michels et al., 1995; Dalla Torre et al., 1997). For examples, the $\mathrm{C}_{1-6}$ gas yield from kerogen cracking is lower under hydrous conditions than under anhydrous conditions (Tannenbaum and Kaplan, 1985); kerogen hydrous pyrolysis forms a larger amount of $\mathrm{CO}_{2}$ gas (Lewan, 1997; Cooles et al., 1987; Price and Wenger, 1992; Andresen et al., 1994; Seewald et al., 1998); it is considered that there is an obvious hydrogen exchange between water and cracking products,

*Corresponding author (e-mail: xmxiao@gig.ac.cn)

Copyright $@ 2009$ by The Geochemical Society of Japan. which is used to account for the heavier hydrogen isotope ratios of the hydrous pyrolysis products than the anhydrous pyrolysis products in the isotopically labeled experiment (Koepp, 1978; Hoering, 1984; Schimmelmann et al., 2001). However, not all geochemists believe the hydrogen exchange between generated products and water is significant enough to affect the hydrogen isotopes of a crude oil. Schoell (1984a, b) held a viewpoint that the carbon and hydrogen isotopic components of normal oil come from its parent materials and are not sensitive to post-alterations, but for the high mature oil and condensate. Lewan et al. (1979) claimed that water cannot obviously affect the hydrogen at carbon bond of hydrous pyrolysis products. Yeh and Epstein (1981) found there is a greater difference in hydrogen isotopic data between formation water and crude oils from numerous petroleum reservoirs in the world and believed the hydrogen isotope exchange between water and cracking products of organic matters could not alter significantly the $\delta \mathrm{D}$ val- 
ues of crude oils (Hitchon and Friedman, 1969; Kharaka et al., 1973). Therefore, it is still a question on how water affects the hydrogen isotopic compositions of products generated from kerogens, especially oil cracking.

Since some commercial gas reservoirs originated from oil cracking have been recently reported (e.g., Zhao et al., 2001, 2006; Chen et al., 2002; Hou et al., 2004; Zhang et al., 2004; Zhang and Zhu, 2006; Zhu et al., 2006; Sun et al., 2007; Wang, Z. C. et al., 2007), thermal pyrolysis experiments become an important way to investigate the processes, mechanisms and conditions of oil cracking, as well as the chemical compositions and isotope fractionations of oil-cracking gas (Tsuzuki et al., 1999; Tang et al., 2000; Hill et al., 2003; Tian et al., 2007). Almost all pyrolysis experiments related to oil cracking are carried out under anhydrous conditions (e.g., Zhang et al., 2006; Tian et al., 2007; Wang, T. S. et al., 2007). There is few paper (e.g., Curiale et al., 1992; Tsuzuki et al., 1999) to discuss oil cracking under hydrous conditions, but the work were not related to a comparison of the gas yields between anhydrous and hydrous pyrolysis conditions and did not discuss carbon and hydrogen isotope ratios of the gaseous products from oil cracking. In this study, laboratory pyrolysis experiments of a selected crude oil sample were performed under hydrous and anhydrous conditions in a sealed gold tube system. The objective of this paper is to investigate the influence of water on the yields and carbon and hydrogen isotopic fractionations of generated hydrocarbon gases from the early stage of oil cracking, and to discuss the process and possible mechanisms related to this influence.

\section{EXPERIMENTAL}

\section{Samples}

The crude oil sample for the pyrolysis experiment was collected from the Triassic reservoir sandstone with a burial depth of 4609-4625 m from the Well LN14 in the Tarim Basin, NW China. It is a normal oil with a density of $0.8397 \mathrm{~g} / \mathrm{cm}^{3}$, a viscosity of $4.18 \mathrm{mPa} \cdot \mathrm{s}$ at $50^{\circ} \mathrm{C}$, and a sulfur and wax content of $0.30 \%$ and $4.43 \%$, respectively (Tian et al., 2006). The oil includes $78.8 \%$ of saturates, $11.6 \%$ of aromatics and $9.6 \%$ of non-hydrocarbons, and the single $n$-alkane compounds from the saturates have a $\delta^{13} \mathrm{C}$ and $\delta \mathrm{D}$ value of $-35--32 \%$ and $-103--68 \%$, respectively (Jin, 2007). The $\delta \mathrm{D}$ value of water used in this experiment is $-4.8 \%$ developed by Research Center of Geochemical Reference Materials, Institute of Geophysical and Geochemical Exploration, China.

\section{Pyrolysis experiments}

The experiments include two sets: pure oil (the set A), and oil + water (the set $\mathrm{H}$ ) (oil: water $=1: 1$, water salinity $=3.5 \%)$. The pyrolysis experiment was carried out in a sealed gold tube system with a constant pressure. Details of the experiment were described in literatures (Tang and Behar, 1995; Tang et al., 2005) and are summarized briefly here. The gold tubes were heated at $800^{\circ} \mathrm{C}$ for 20 minutes in a muffle furnace to remove any residual organic materials before it was used. The oil sample was diluted by dichloromethane and a certain amount of the mixture (with $10-30 \mathrm{mg}$ oil) was then transferred into a gold tube with a syringe. The gold tube with the sample was placed in a dry place for a few days to remove the dichloromethane. The water, for the set $\mathrm{H}$, was then injected into the gold tube with the oil sample by an oil/ water ratio of 1 . The open end of the gold tube was sealed in an argon air environment with the other pre-sealed end being immersed in water to avoid burning out the sample at high temperature. Finally, the sealed gold tubes were put into a stainless steel autoclave and were ready for pyrolysis. The experimental conditions were set at $P=$ $21 \mathrm{MPa}, T=370^{\circ} \mathrm{C}$, and times ranging from 1 day to 7 days, having a thermal stress of EasyRo (a widely used thermal maturity indicator, Sweeny and Burham, 1990) values from $1.13 \%\left(1\right.$ day' heating at $\left.370^{\circ} \mathrm{C}\right)$ to $1.49 \%(7$ days' heating at $370^{\circ} \mathrm{C}$ ), in the early stages of oil cracking.

\section{The analysis of products}

Gas was released from the gold tube in a special device described by Pan et al. (2006). The device is connected with an Agilent $6890 \mathrm{~N} \mathrm{GC}$, and can drive a portion of gas directly to enter into the GC for gas composition analysis. The detector is the FID and Helium was used as the carrier gas. The heating program of the GC oven was $70^{\circ} \mathrm{C}$ for $4 \mathrm{~min}$, ramped from 70 to $130^{\circ} \mathrm{C}$ at $15^{\circ} \mathrm{C} / \mathrm{min}$, then from 130 to $180^{\circ} \mathrm{C}$ at $25^{\circ} \mathrm{C} / \mathrm{min}$, and thereafter held at $180^{\circ} \mathrm{C}$ for $4 \mathrm{~min}$.

The carbon isotopic analysis was performed on a VG Isochrom II interfaced to a HP5890 GC. The GC was equipped with a Poraplot $\mathrm{Q}$ chromatograph column (30 $\mathrm{m} \times 0.32 \mathrm{~mm} \times 20 \mu \mathrm{m})$ and Helium was used as the carrier gas. The heating program of the $\mathrm{GC}$ oven is $40^{\circ} \mathrm{C}$ for $3 \mathrm{~min}$, followed by a heating ramp to $180^{\circ} \mathrm{C}$ at $20^{\circ} \mathrm{C} / \mathrm{min}$, where it was held for $5 \mathrm{~min}$. The replicated carbon isotope analyses of a standard gas showed the standard deviation of less than $0.2 \%$ in the measurement.

The hydrogen isotopic analysis was performed on a Finnigan MAT Delta plus-XL mass spectrometer (GC/TC/ IRMS) linked to a HP $6890 \mathrm{~N}$ GC via a GC-C III interface. The GC was equipped with a $30 \mathrm{~m} \times 0.32 \mathrm{~mm}$ i.d. CP-PoraPlotQ column (film thickness 0.25 um). Helium was used as carrier gas. The GC oven temperature was initially held at $50^{\circ} \mathrm{C}$ for $7 \mathrm{~min}$, ramped from 50 to $180^{\circ} \mathrm{C}$ at $20^{\circ} \mathrm{C} / \mathrm{min}$. The $\mathrm{GC}$ inlet temperature is $200^{\circ} \mathrm{C}$. The permitted standard deviation for the hydrogen isotopic analysis is less than 5\% in this study. 


\section{RESULTS}

Gas yields and carbon and hydrogen isotopic ratios of the generated gases from cracking of the oil under hydrous and anhydrous conditions are presented in Table 1 . The following results can be achieved.

(1) Yield of $C_{1-5}$ alkanes generated from the hydrous cracking is obviously lower than that from the anhydrous cracking

In the present experiments, the yields of almost all kinds of gaseous alkanes from the oil cracking under the hydrous and anhydrous conditions show an increase with increasing heating duration although the increased extent is variable with different components and different pyrolysis duration. In the first 3 days' pyrolysis, the yields of all components increase rapidly with increasing pyrolysis time; then the yields of $\mathrm{C}_{1-4}$ alkanes still increases stably, but the $n-\mathrm{C}_{5} \mathrm{H}_{12}$ yield increases slowly and the $i$ $\mathrm{C}_{5} \mathrm{H}_{12}$ yield turns to decrease slightly, showing an obvious occurrence of secondary cracking of $n-\mathrm{C}_{5} \mathrm{H}_{12}$ (Fig. 1). Compared with the anhydrous pyrolysis, the hydrous pyrolysis of the oil generates an obviously lower amount of the $\mathrm{C}_{1-5}$ hydrocarbon. Taken the results after 7 days' pyrolysis (EasyRo $=1.49 \%$ ) as a comparison, the $\mathrm{CH}_{4}$, $\mathrm{C}_{2} \mathrm{H}_{6}, \mathrm{C}_{3} \mathrm{H}_{8}, \mathrm{C}_{4} \mathrm{H}_{10}$ and $\mathrm{C}_{5} \mathrm{H}_{12}$ yields under the anhydrous pyrolysis condition reach $26.8 \mathrm{ml} / \mathrm{g}, 14.9 \mathrm{ml} / \mathrm{g}, 14 \mathrm{ml} / \mathrm{g}$, $11.8 \mathrm{ml} / \mathrm{g}$ and $8.7 \mathrm{ml} / \mathrm{g}$, respectively, greater by $5.2 \mathrm{ml} / \mathrm{g}$, $1.7 \mathrm{ml} / \mathrm{g}, 1.4 \mathrm{ml} / \mathrm{g}, 2.1 \mathrm{ml} / \mathrm{g}$ and $1.8 \mathrm{ml} / \mathrm{g}$, respectively, than under the hydrous pyrolysis condition.

The previous studies have also found that water can inhibit the pyrolysis process of kerogen or other organic matters and it has been believed that the inhabitation of pressure is more obvious in hydrous system than that in anhydrous system (Hesp and Rigby, 1973; Price, 1993; Michels et al., 1995; Dalla Torre et al., 1997). However, the water in the tube should keep its liquid phase to a great extent at $370^{\circ} \mathrm{C}$ and $21 \mathrm{MPa}$ of this experimental condition according to phase diagram, the water partial pressure is not significant as compared with the outside pressure. The pressure of the gold tube system is maintained through water medium outside (Tang et al., 2005; Pan et al., 2006). Therefore, the pressures in the hydrous and anhydrous pyrolysis experiment are not obviously different and the water partial pressure could not explain the lower yields of the $\mathrm{C}_{1}-\mathrm{C}_{5}$ alkanes in the hydrous pyrolysis experiment.

(2) Carbon isotopic values of $C_{1-3}$ hydrocarbons from hydrous cracking are lighter than those from anhydrous cracking

The general change trends of the carbon isotope values of $\mathrm{C}_{1-3}$ hydrocarbons generated from oil cracking with increasing thermal stress are similar between the two pyrolysis conditions although a full change trend of the

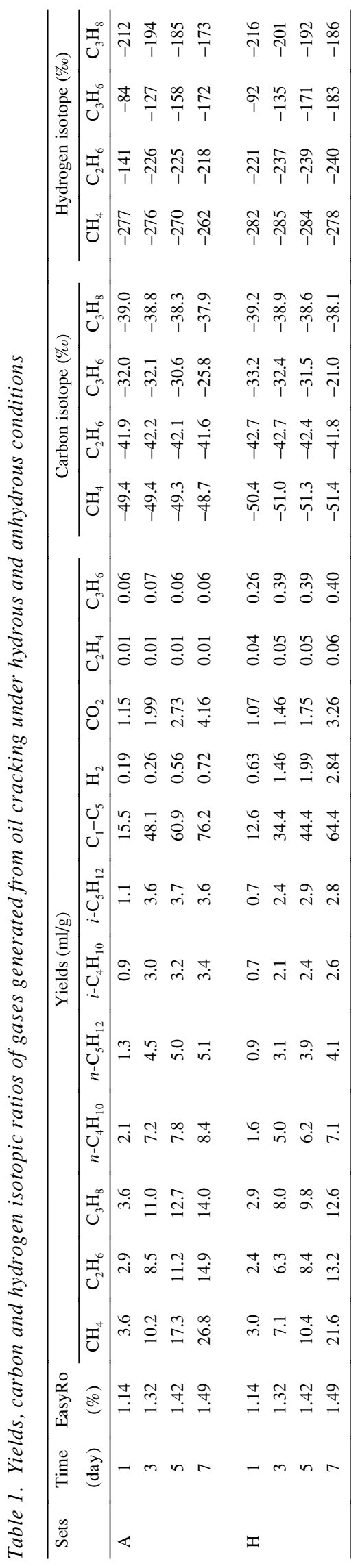

Oil cracking to gas under hydrous and anhydrous conditions 

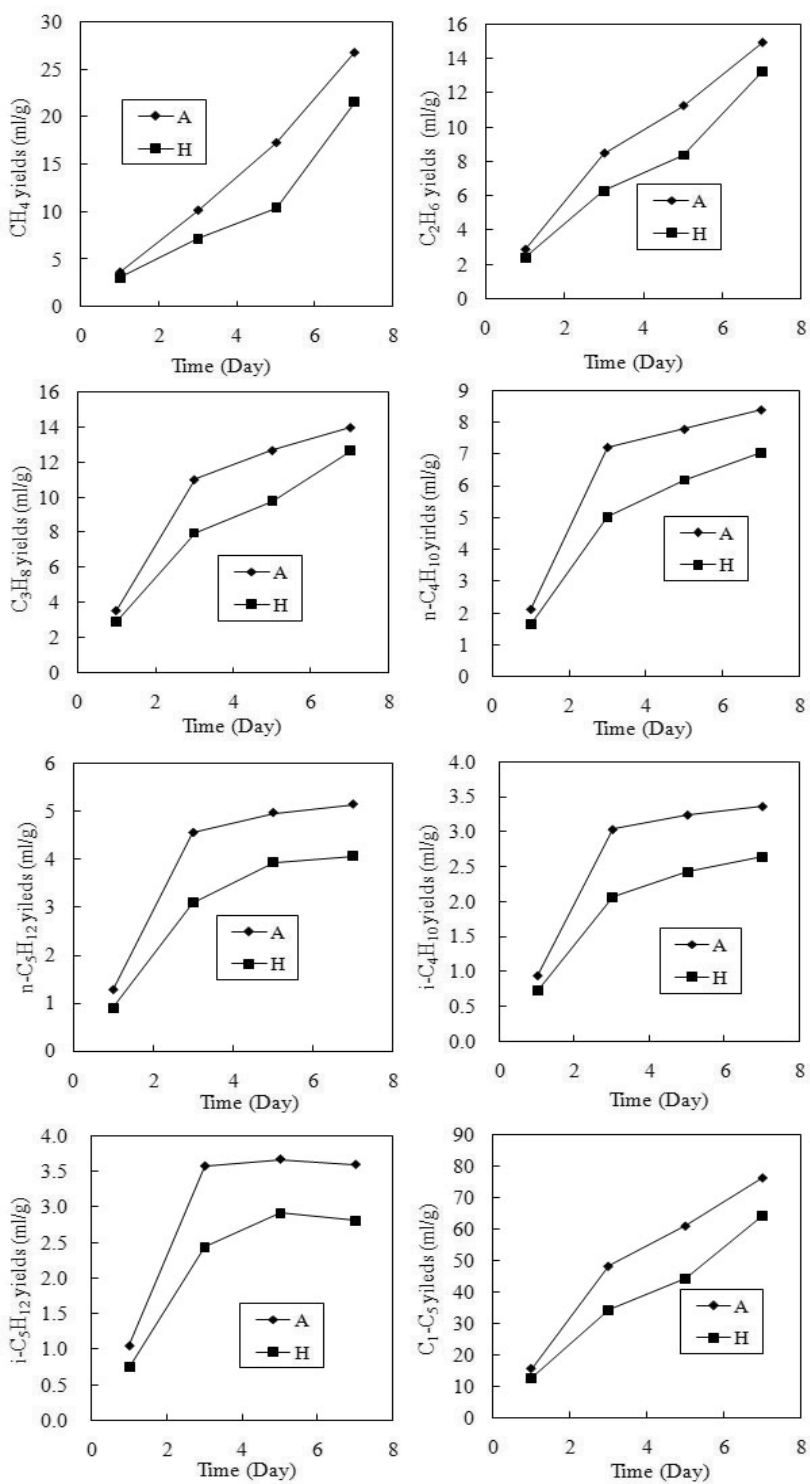

Fig. 1. The yields of $C_{1-5}$ hydrocarbons generated from oil cracking under hydrous (the set $H$ ) and anhydrous (the set $A$ ) conditions.

$\delta^{13} \mathrm{C}_{1}$ values from the hydrous pyrolysis experiment is not observed owing to the limited thermal stress range investigated (Fig. 2). In the anhydrous pyrolysis condition, the $\delta^{13} \mathrm{C}_{1}$ and $\delta^{13} \mathrm{C}_{2}$ values firstly become lighter and than turn to be heavier with further increasing thermal stress, and the $\delta^{13} \mathrm{C}_{3}$ values show a simple increase as thermal stress increases (Fig. 2). In the hydrous pyrolysis condition, the $\delta^{13} \mathrm{C}_{1}$ values show a decrease from the present data, but should turn to be an increase at a higher thermal stress ( $>1.49 \%$ of EasyRo) according to the methane carbon isotope fractionation of oil-cracking gas (e.g., Xiong et al., 2004; Tian et al., 2007); the turn
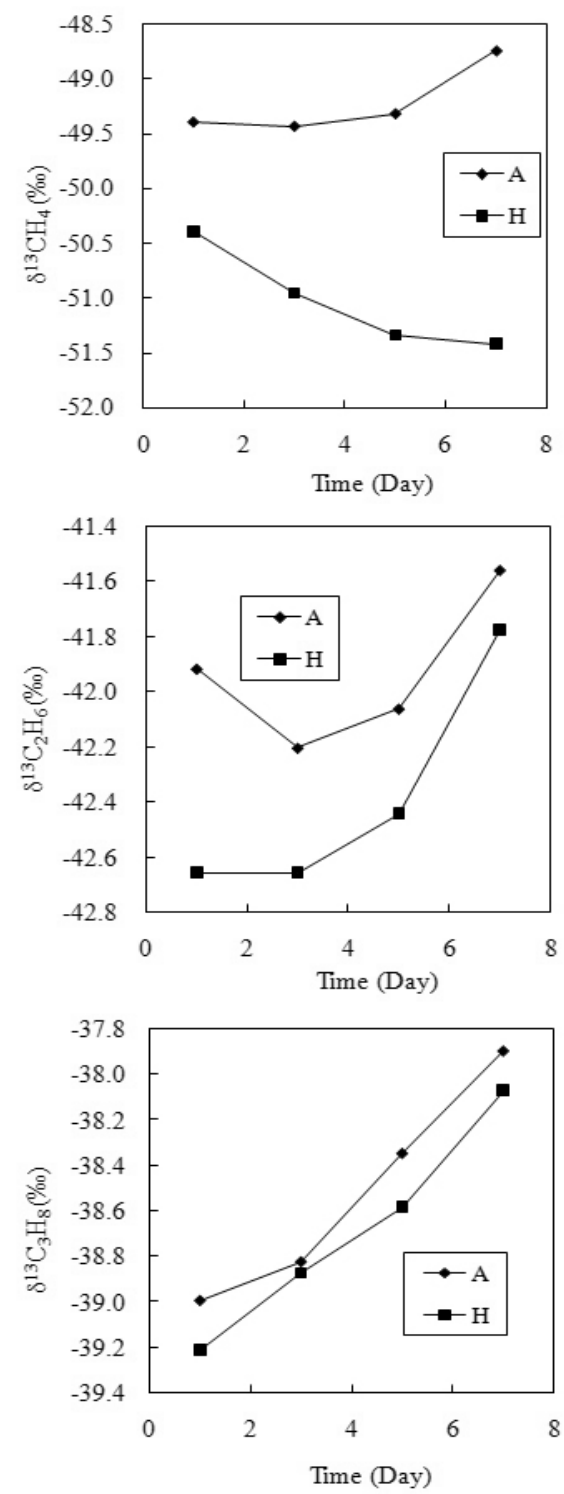

Fig. 2. Changes in carbon isotopic ratios of $C_{1-3}$ hydrocarbons generated from oil cracking under hydrous (the set $H$ ) and anhydrous (the set $A$ ) conditions.

point of $\delta^{13} \mathrm{C}_{2}$ values seem occurring between the 1 days' pyrolysis and the 3 days' pyrolysis according the curve trend; and the $\delta^{13} \mathrm{C}_{3}$ values, as in the anhydrous pyrolysis condition, also show a stable increase with increasing thermal stress (Fig. 2). The significant difference between the two pyrolysis experiments is in their carbon isotopic values. The present data indicate that the carbon isotopic values of the $\mathrm{C}_{1-3}$ hydrocarbons generated from the hydrous cracking are obviously lighter than those from the anhydrous cracking. Their differences of $\delta^{13} \mathrm{C}_{1}, \delta^{13} \mathrm{C}_{2}$ and $\delta^{13} \mathrm{C}_{3}$ values reach $1.0-2.7 \%$, $0.2-0.8 \%$ and $0.2-0.3 \%$, respectively, for the maturity stages investigated (Table 

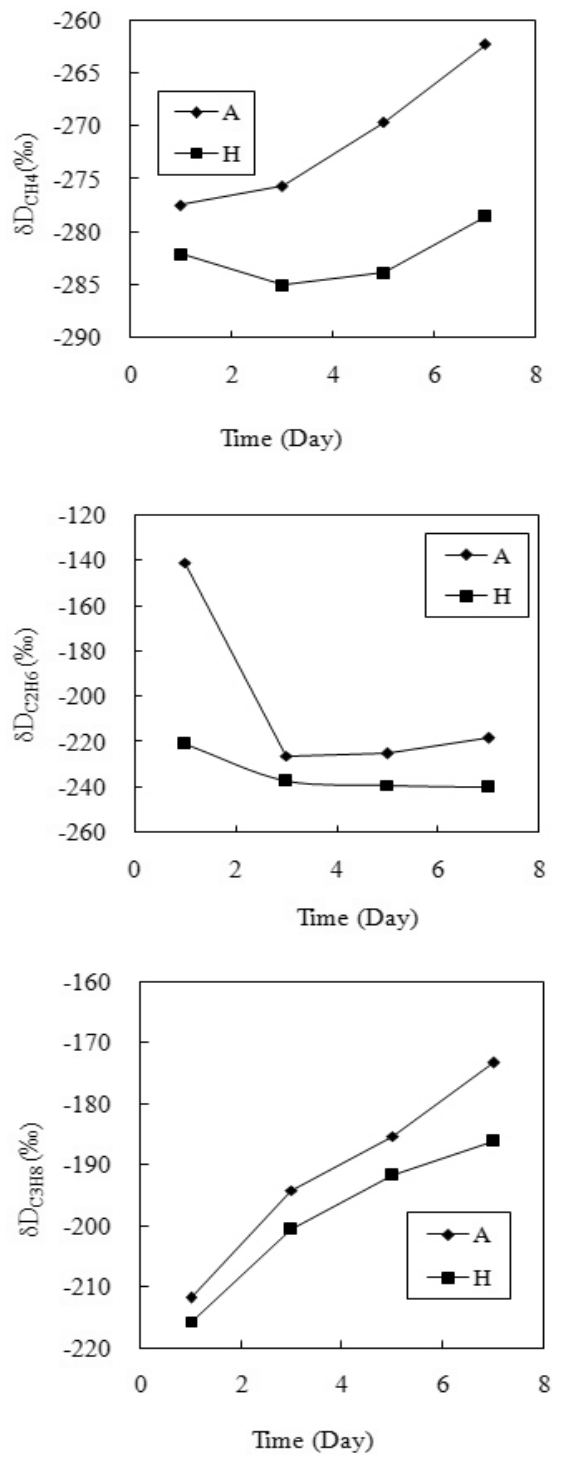

Fig. 3 Changes in hydrogen isotopic ratios of $C_{1-3}$ hydrocarbons generated from oil cracking under hydrous (the set $H$ ) and anhydrous (the set $A$ ) conditions.

1). Thus, the present result has indicated that water has an obvious effect on carbon isotopic fractionations of the generated hydrocarbons from oil cracking in the presence of water.

(3) Hydrogen isotope values of $C_{1-3}$ hydrocarbons from hydrous cracking are lighter than those from anhydrous cracking

The change trends in hydrogen isotopic ratios of $\mathrm{C}_{1-3}$ hydrocarbons from the oil cracking under the two pyrolysis conditions are presented in Fig. 3. In the hydrous pyrolysis conditions, the $\delta \mathrm{D}_{\mathrm{CH} 4}$ values become a slight decrease firstly and then turn to increase, and it can be predicted that the $\delta \mathrm{D}_{\mathrm{C} 2 \mathrm{H} 6}$ values should turn to be heavier at a higher maturity ( $>1.49 \%$ of EasyRo) according to the hydrogen isotopic fractionation pattern of gas generated from organic matter. In the anhydrous pyrolysis condition, the $\delta \mathrm{D}_{\mathrm{CH} 4}$ values show an increase with increasing thermal stress, and its turn point might occurs in a lower maturity ( $<1.13 \%$ of EasyRo) than that investigated; the $\delta \mathrm{D}_{\mathrm{C} 2 \mathrm{H} 6}$ values have a similar change trend of its carbon isotope ratios, with an obvious turn point occurring at the 3 days' pyrolysis. The $\delta \mathrm{D}_{\mathrm{C} 3 \mathrm{H} 8}$ values in both anhydrous and hydrous pyrolysis conditions become simply heavier with increasing thermal stress. The obvious difference between the two pyrolysis experiments is that the $\delta \mathrm{D}_{\mathrm{CH} 4}, \delta \mathrm{D}_{\mathrm{C} 2 \mathrm{H} 6}, \delta \mathrm{D}_{\mathrm{C} 3 \mathrm{H} 8}$ and values of hydrocarbon gases generated under the hydrous pyrolysis conditions are lighter than those from the anhydrous pyrolysis, with a difference reaching 5-16\%o, 22-80\%o and 4-13\%o, respectively (Table 1), indicating water has a stronger influence on hydrogen isotopic fractionations than carbon isotopic fractionations.

\section{DISCUSSION}

As pointed out above, water affects the $\delta \mathrm{D}$ values of hydrocarbons generated from kerogen cracking under hydrous pyrolysis conditions through hydrogen exchange reaction with kerogen (Hoering, 1984; Schimmelmann $e t$ $a l ., 2001)$. However, there is not an obvious hydrogen exchange between the water and oil-cracking products in the hydrous experiment for oil cracking. The main evidences are summarized below.

(1) Kerogen cracking under hydrous conditions generates a large amount of methane (Helgeson et al., 1993) and the generated gas hydrocarbons are characterized by a heavier hydrogen isotope value compared with kerogen cracking under anhydrous condition (Hoering, 1984). However, this phenomenon is not found from the present experiment. The $\delta \mathrm{D}$ value of water used in the experiment is $-4.8 \%$, much heavier than that of the $n$-alkane $(-103--68 \%)$ (Jin, 2007), a main component of the studied oil. The $\delta \mathrm{D}$ values of $\mathrm{C}_{1-3}$ hydrocarbons generated from the oil under the hydrous pyrolysis conditions are in fact lighter by $4-80 \%$ o than under the anhydrous pyrolysis conditions (Table 1), indicating that the hydrogen exchange between water and oil-cracking products is not the main factors dominating the hydrogen isotopic compositions of $\mathrm{C}_{1-3}$ hydrocarbons at the early stage of oil cracking in the presence of water.

(2) As compared with the anhydrous pyrolysis conditions (Fig. 4), the yield of $\mathrm{H}_{2}$ generated from the oil cracking in the hydrous condition is higher by $0.5-2.5 \mathrm{ml} / \mathrm{g}$, which further tests that the water has certainly affected oil-cracking reactions. The $\mathrm{H}_{2}$ derived from oil cracking 

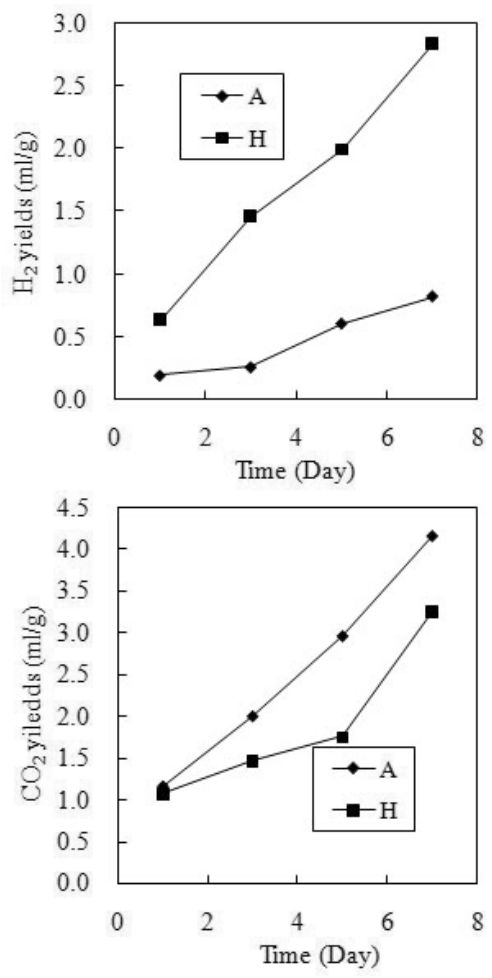

Fig. 4. Changes in yields of $\mathrm{H}_{2}$ and $\mathrm{CO}_{2}$ generated from oil cracking under hydrous (the set $H$ ) and anhydrous (the set A) conditions.

in the presence of water has two possible sources: oil cracking itself and water decomposition. If water was thermally decomposed to form $\mathrm{H}_{2}$, the oxygen from the water would combine with carbon from oil cracking to form a greater amount of carbon dioxide. However, the carbon dioxide yield under the hydrous pyrolysis conditions is obviously lower (by $0.5-1.5 \mathrm{ml} / \mathrm{g}$ ) than that under the anhydrous pyrolysis conditions (Fig. 4), which implicates the greater $\mathrm{H}_{2}$ in the hydrous pyrolysis experiment mainly comes also from oil cracking, rather than from the direct decomposition of water. Further comparison between the two experiment conditions of oil cracking shows that the alkenes yield from the hydrous pyrolysis is also greater than that from the anhydrous pyrolysis (Fig. 5), which implicates that the formation of both alkene and $\mathrm{H}_{2}$ would be affected by the same factors.

Another possible reason which should be addressed for the isotopic ratio differences between the hydrous and anhydrous pyrolysis conditions is if there is an obvious difference in their maturity. Besides temperature, pressure has an influence on thermal pyrolysis reactions of organic matter although the extent is limited. As discussed above, there is no significant water partial pressure in the
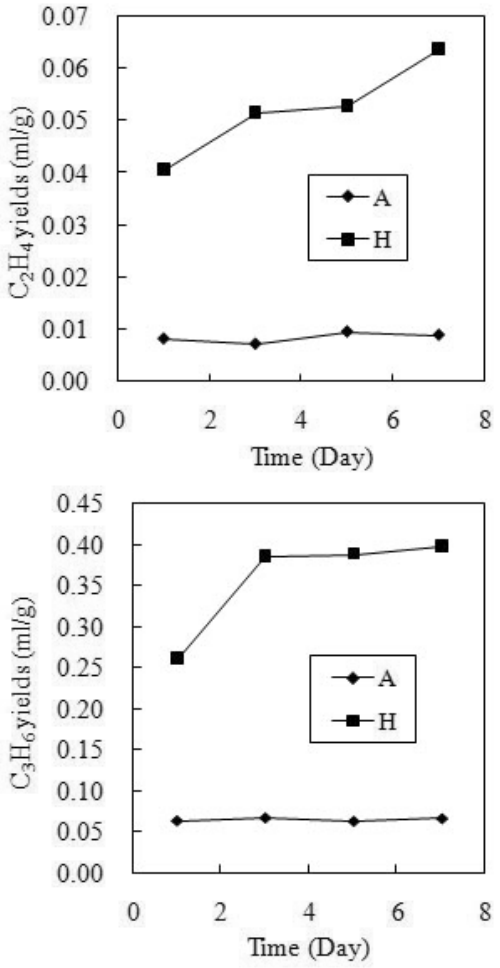

Fig. 5. A comparison of yields of ethene and propene generated from oil cracking between hydrous (the set H) and anhydrous (the set A) conditions.

gold-tube system under the hydrous condition applied in this study, and it is believed that the pressure difference could not lead to a significant maturity difference between the two experimental conditions. Moreover, assumed the $\mathrm{C}_{1-5}$ yield can reflect the extent of the thermal pyrolysis reactions of oil cracking, a comparison can be also made between the hydrous and anhydrous conditions for their isotopic ratios. The 7 days' duration under the hydrous condition gives a $\mathrm{C}_{1-5}$ yield of $64.4 \mathrm{ml} / \mathrm{g}$, only a little more than the yield from the 5 days' duration under the anhydrous condition $(60.9 \mathrm{ml} / \mathrm{g})$, but the carbon and hydrogen isotope ratios of its $\mathrm{C}_{1-3}$ hydrocarbons are obvious lighter than those under the anhydrous condition (Table 1), which implicates the maturity difference (even if exists) could not well explain the isotopic ratio difference between the hydrous and anhydrous pyrolysis conditions.

According to the free radical reaction mechanism (Huang et al., 1974), the carbon-carbon bond of alkanes (the main components of the studied oil) is broken to generate alkyls, the alkyls loss hydrogen to form alkenes or combines with hydrogen to form smaller molecular weight alkanes (Fig. 6), and the combination of dissociated hydrogen with each other will form $\mathrm{H}_{2}$. This is the main 


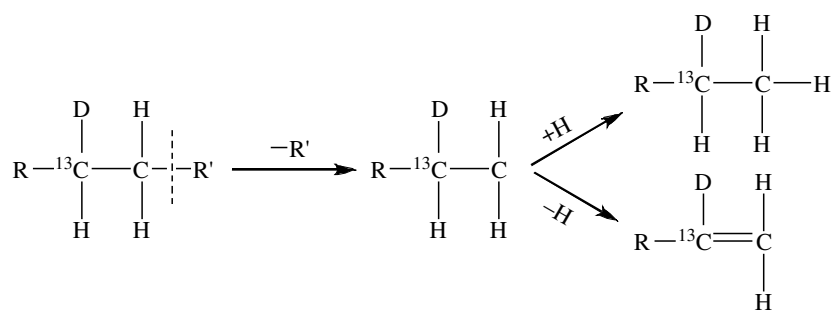

Fig. 6. A sketch map showing free radical reactions in oilcracking process.

source of $\mathrm{H}_{2}$ and alkene from the experiment. Thus, it is proposed that the greater amounts of alkene and $\mathrm{H}_{2}$ generated from oil cracking under the hydrous pyrolysis conditions than under the anhydrous pyrolysis conditions could be because water affects the radical reaction to inhibit the combination between alkyl and hydrogen.

A support on this assumption can be also obtained from an analysis on the relationship between the yields and carbon and hydrogen isotopic ratios of the hydrocarbon gases generated from oil cracking under the both experiment conditions. Gaseous hydrocarbons generated from oil cracking are mainly derived from combinations between alkyl and alkyl or alkyl and hydrogen in the process of free radical reactions (Huang et al., 1974). If these combinations between the radicals are inhibited, the yields of alkenes and $\mathrm{H}_{2}$ will increase and the yield of alkanes will decrease. As presented in Fig. 1, in the early stage of oil cracking, the yields of $\mathrm{C}_{1-5}$ hydrocarbons generated under the hydrous pyrolysis conditions are obviously lower than those under the anhydrous pyrolysis conditions, which can be considered as a result mainly from the inhabitation of water to the combination between the radicals. Alkenes are less stable than alkanes and liable to combine with hydrogen to form alkanes, so that it is believed that the gas yield differences between the two pyrolysis conditions will gradually decrease with further increasing the extent of oil cracking.

The differences of carbon and hydrogen isotopic ratios between hydrous and anhydrous conditions can be explained by the isotopic fractionation principle of organic matter cracking to gas and the inhibited free radical reaction of oil cracking in the presence of water. Since the zero potential energies of ${ }^{13} \mathrm{C}$ and $\mathrm{D}$ are lower than those of ${ }^{12} \mathrm{C}$ and ${ }^{1} \mathrm{H}$ (Zheng and Chen, 2000) and the bond energies of ${ }^{13} \mathrm{C}-{ }^{12} \mathrm{C}$ and $\mathrm{C}-\mathrm{D}$ are larger than those of ${ }^{12} \mathrm{C}-$ ${ }^{12} \mathrm{C}$ and $\mathrm{C}-{ }^{1} \mathrm{H}$, respectively, the components of oil, such as alkanes combined by ${ }^{12} \mathrm{C}$ and ${ }^{1} \mathrm{H}$ has a lower stability and is liable to be cracked to form an earlier product (Fig. 7 ), which leads to a relatively light $\delta^{13} \mathrm{C}$ and $\delta \mathrm{D}$ values of the gaseous alkanes generated from the early stage of oil cracking (Figs. 2 and 3). Compared with an alkane with the same carbon number, an alkene is much enriched

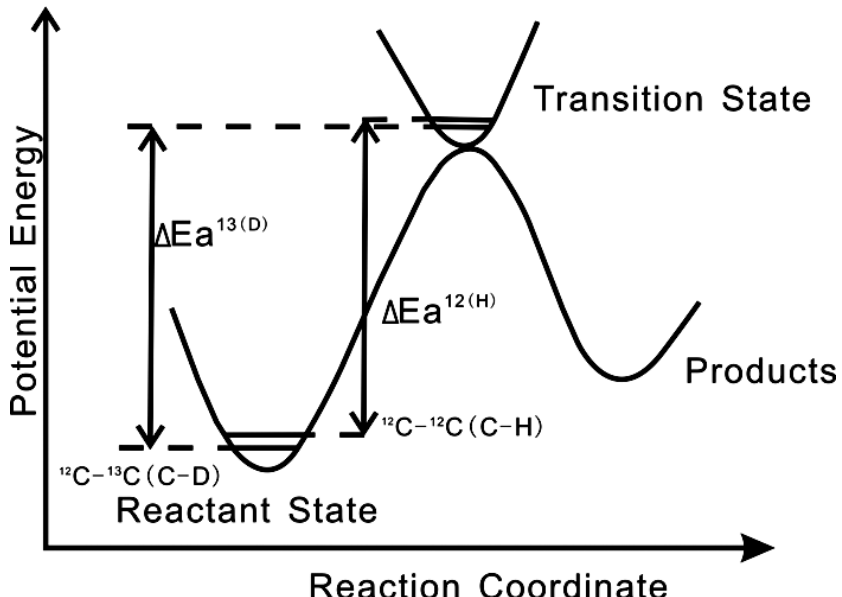

Fig. 7. Potential energy diagram for carbon and hydrogen isotopic fractionations in free radical reactions (modified after Tang et al., 2000).

in ${ }^{13} \mathrm{C}$ and $\mathrm{D}$, and their differences can reach $6.0-17.0 \%$ o and $1.0-128.0 \%$, respectively, according the present study (Table 1). As discussed above, since water inhibits the free radical reactions, oil cracking in the hydrous pyrolysis condition forms a larger amount of alkenes and a smaller amount of alkanes than does in the anhydrous pyrolysis condition. This implicates that a more portion of enriched ${ }^{13} \mathrm{C}$ and $\mathrm{D}$ alkenes is not transferred to gaseous alkanes under the hydrous pyrolysis condition, which leads to lighter carbon and hydrogen isotopic ratios of gaseous alkanes generated from oil cracking under the hydrous pyrolysis conditions than under the anhydrous pyrolysis conditions at the early stage of oil cracking.

In general, the present study proposes that in the early stage of oil cracking in the presence of water, hydrogen atom of water does not significantly enter into hydrocarbon molecular to increase the yields of low molecular hydrocarbons, but water inhibits the combination between alkyl and hydrogen through affecting some free radical reactions to decrease the yields and carbon and hydrogen isotopic ratios of the generated gas hydrocarbons.

\section{Conclusion}

A comparison experiment for oil cracking under hydrous and anhydrous conditions by a gold tube confined system leads to the following achievements:

(1) Oil cracking under the hydrous pyrolysis conditions generates a smaller amount of gaseous hydrocarbons and $\mathrm{CO}_{2}$ than under the anhydrous pyrolysis conditions. This difference cannot be explained by the partial pressure of water. The higher yields of alkenes and $\mathrm{H}_{2}$ under the hydrous pyrolysis conditions than under the anhydrous pyrolysis conditions indicates water obviously 
inhibits the combination between alkyl and hydrogen to form alkanes.

(2) The $\mathrm{C}_{1-3}$ hydrocarbons generated from oil cracking under hydrous conditions have an obviously lighter carbon and hydrocarbon isotopic ratios than those under anhydrous conditions, which does not result from the isotopic exchange between oil-cracking products and water.

(3) Water inhibits the combination between alkyl and hydrogen possibly through controlling some free radical reactions to have an influence on the yields and carbon and hydrogen isotope fractionations of gaseous hydrocarbons generated from oil cracking under hydrous conditions.

Acknowledgments-The authors are indebted to Dr. Hiroshi Naraoka and two anonymous reviewers for their insightful comments and suggestions that significantly improved the manuscript. The work was financially supported by the Natural Science Fund for Distinguished Young Scholars (Grant No. 40625011) and the Key Project of Chinese Academy of Science (Grant No. KZCX2-YW-114). This is contribution No. IS1041 from GIGCAS.

\section{REFERENCES}

Andresen, B., Throndsen, T., Barth, T. and Bolstad, J. (1994) Thermal generation of carbon dioxide and organic acids from different source rocks. Org. Geochem. 21, 1229-1242.

Chen, S. J., Fu, X. W., Ma, L. N. and Zhang, X. (2002) Genetic identification method of kerogen-cracked gases and oilcracked gases. Petrol. Geol. \& Exp. 24, 364-371 (in Chinese with English abstract).

Cooles, G. P., Machenzie, A. S. and Parkes, R. J. (1987) Nonhydrocarbons of significance in petroleum exploration: volatile fatty acids and non-hydrocarbons gases. Mineral. Mag. 51, 483-493.

Curiale, J. A., Lundegard, P. D. and Kharka, Y. K. (1992) Hydrous pyrolysis of crude oil in gold-plated reactors. Org. Geochem. 18, 745-756.

Dalla Torre, M., Mählmann, R. and Ernst, W. G. (1997) Experimental study on the pressure dependence of vitrinite maturation Geochim. Cosmochim. Acta 61, 2921-2928.

Helgeson, H. C., Knox, A. M., Owens, C. E. and Shock, E. L. (1993) Petroleum, oil field water, and authigenic mineral assembles: Are they in metastable equilibrium in hydrocarbon reservoirs? Geochim. Cosmochim. Acta 57, 3295-3339.

Hesp, W. and Rigby, D. (1973) The geochemical alteration of hydrocarbons in the presence of water. Erdol Kohle Erdgas 26, 70-76.

Hill, R. J., Tang, Y. C. and Kaplan, I. R. (2003) Insights into oil cracking based on laboratory experiments. Org. Geochem. 34, 1651-1672.

Hitchon, B. and Friedman, I. (1969) Geochemistry and origin of formation waters in the Western Canada Sedimentary Basin-I. Stable isotopes of hydrogen and oxygen. Geochim. Cosmochim. Acta 33, 1321-1349.

Hoering, T. C. (1984) Thermal reaction of kerogen with added water, heavy water and pure organic substances. Org.
Geochem. 5, 267-278.

Hou, D. J., Zhao. Z. Y., Tang, Y. J., Zhu, J. Z. and Xiao, Z. Y. (2004) The geological and geochemical characteristics of oil cracked gas in Kekeya region, Tarim basin. Nat. Gas Geosci. 15, 195-200 (in Chinese with English abstract).

Huang, R. L., Goh, S. H. and Ong, S. H. (1974) The Chemistry of Free Radicals. Edward Amold, London, $244 \mathrm{pp}$.

Jin, Y. B. (2007) The study of n-Tetracosane and crude oil cracking with water. Ph.D. Thesis, Guangzhou Institute of Geochemistry, Chinese Academy of Sciences, Guangzhou, 94 pp. (in Chinese with English abstract).

Kharaka, Y. K., Barry, F. A. F. and Friedman, I. (1973) Isotopic composition of oil-field brines from Kettleman North Dome California and their geologic implications. Geochim. Cosmochim. Acta 37, 1899-1908.

Koepp, M. (1978) D/H isotope exchange reaction between petroleum and water: A contributory determinant for $\mathrm{D} / \mathrm{H}-$ isotope ratios in crude oil? Short Papers of the Fourth International Conference. Geochronology. Cosmochronology. Isotope Geology, USGS Open-File Report 78-701 (Zartman, R. E., ed.), 221-222, U.S. Geological Survey.

Lewan, M. D. (1997) Experiments on the role of water in petroleum formation. Geochim. Cosmochim. Acta 61, 36913723.

Lewan, M. D., Winters, J. C. and McDonald, J. H. (1979) Generation of oil-like pyrolyszates from organic-rich shales. Science 203, 897-899.

Michels, R., Landais, P., Torkelson, B. E. and Philp, R. P. (1995) Effects of effluents and water pressure on oil generation during confined pyrolysis and high-pressure hydrous pyrolysis Geochim. Cosmochim. Acta 59, 1589-1604.

Pan, C. C., Yu, L. P., Liu, J. Z. and Fu, J. M. (2006) Chemical and carbon isotopic fractionations of gaseous hydrocarbons during abiogenic oxidation. Earth Planet. Sci. Lett. 246, 70-89.

Price, L. C. (1993) Thermal stability of hydrocarbons in nature: Limits, evidence, characteristics and possible controls. Geochim. Cosmochim. Acta 57, 3261-3280.

Price, L. C. and Wenger, L. M. (1992) The influence of pressure on petroleum generation and maturation as suggested by aqueous pyrolysis. Org. Geochem. 19, 141-159.

Schimmelmann, A., Bondon, J. P., Lewan, M. D. and Wintsch, R. P. (2001) Experimental controls on D/H and ${ }^{13} \mathrm{C} /{ }^{12} \mathrm{C}$ ratios of kerogen, bitumen and oil during hydrous pyrolysis. Org. Geochem. 32, 1009-1018.

Schoell, M. (1984a) Application of biological markers in petroleum geochemistry. Advances in Petroleum Geochemistry (Brooks, L. and Welte, D., eds.), 1, 215-245, Academic Press, London.

Schoell, M. (1984b) Recent advances in petroleum isotope geochemistry. Org. Geochem. 6, 645-663.

Seewald, J. S., Bryan, C. B. N. and Whelan, J. K. (1998) Laboratory and theoretical constraints on the generation and composition of natural gas. Geochim. Cosmochim. Acta 62, 1599-1617.

Sun, W., Liu, S. G., Ma, Y. S., Cai, X. Y., Xu, G. S., Wang, G. Z., Yong, Z. Q., Yuan, H. D. and Pan, C. L. (2007) Determination and quantitative simulation of gas pool formation process of sinian cracked gas in Weiyuan-Ziyang area, 
Sichuan Basin. Acta Geol. Sin. 81, 1153-1159 (in Chinese with English abstract).

Sweeny, J. J. and Burham, A. K. (1990) Evaluation of a simple model of vitrinite reflectance based on chemical kinetics. AAPG Bull. 74(10), 1559-1570.

Tang, Y. and Behar, F. (1995) Rate constants of $n$-alkanes generation from type kerogen in open and closed pyrolysis systems. Energy \& Fuels 3, 507-512.

Tang, Y., Perry, J. K., Jenden, P. D. and Schoell, M. (2000) Mathematical modeling of stable carbon isotope ratios in natural gases. Geochim. Cosmochim. Acta 64, 2673-2687.

Tang, Y., Huang, Y., Ellis, G. S., Wang, Y., Kralert, P. G., Gillaizeau, B., Ma, Q. S. and Hwang, R. (2005) A kinetic model for thermally induced hydrogen and carbon isotope fractionation of individual $n$-alkanes in crude oil. Geochim. Cosmochim. Acta 69, 4505-4520.

Tannenbaum, E. and Kaplan, I. R. (1985) Low-Mr hydrocarbons generated during hydrous and dry pyrolysis of kerogen. Nature 317, 708-709.

Tian, H., Wang, Z. M., Xiao, Z. Y., Li, X. Q. and Xiao, X. M. (2006) Oil cracking to gases: Kinetic modeling and geological significance. Chinese Sci. Bull. 51, 1821-1827.

Tian, H., Xiao, X. M, Wilkins, R. W. T., Li, X. Q. and Gan, H. J. (2007) Gas sources of the YN2 gas pool in the Tarim Basin-Evidence from gas generation and methane carbon isotope fractionation kinetics of source rocks and crude oils. Mar. Petrol. Geol. 24, 29-41.

Tsuzuki, N., Takeda, N., Suzuki, M. and Yokoi, K. (1999) The kinetic modeling of oil cracking by hydrothermal pyrolysis experiments. Int. J. Coal. Geol. 39, 227-250.

Wang, T. S., Geng, A. S., Xiong, Y. Q. and Geng, X. H. (2007) Mass balance calculation of the pyrolysates generated from marine crude oil: A prediction model of oil cracking gas resources based on solid bitumen in reservoir Chinese Sci. Bull. 52, 836-842.

Wang, Z. C., Zhao, W. Z., Zhang, S. C., Wang, H. J. and Yu, Q. (2007) Control of coupling among three major factors for formation of high-efficiency gas reservoir-A case study on the oolitic beach gas reservoir in Feixianguan Formation in the northeast Sichuan Basin. Chinese Sci. Bull. 52 (Supplement 1), 156-166.

Xiong, Y. Q., Geng, A. S. and Liu, J. Z. (2004) Kineticsimulating experiment combined with GC-IRMS analysis: application to identification and assessment of coal-derived methane from Zhongba Gas Field (Sichuan Basin, China). Chem. Geol. 213, 325-338.

Yeh, H. W. and Epstein, S. (1981) Hydrogen and carbon isotope of petroleum and related organic matter. Geochim. Cosmochim. Acta 45, 753-762.

Zhang, H. Z., Geng, A. S., Xiong, Y. Q., Wang, T. S. and Liu, J. Z. (2006) Kinetic simulation of natural gas generation and its geological application. Nat. Gas Ind. 26, 19-24 (in Chinese).

Zhang, S. C. and Zhu, G. Y. (2006) Gas accumulation characteristics and exploration potential of marine sediments in Sichuan Basin. Acta Petrolei Sin. 27, 1-8 (in Chinese with English abstract)

Zhang, S. C., Zhao, W. Z., Wang, F. Y., Chen, J. P., Xiao, Z. Y., Zhong, N. N. and Song, F. Q. (2004) Palwozoic oil cracking gas accumulation history from eastern part of the Tarim basin-A case study of the YN2 gas reservoir. Nat. Gas Geosci. 15, 441-451 (in Chinese with English abstract).

Zhao, M. J., Zhang, S. C. and Liao, Z. Q. (2001) The cracking gas from crude oil and its significance in gas exploration. Petrol. Expl. Dev. 28, 47-52 (in Chinese with English abstract).

Zhao, W. Z., Wang, Z. C. and Wang, Y. G. (2006) Formation mechanism of highly effective gas pools in the Feixianguan Formation in the NE Sichuan Basin. Geol. Rev. 52, 708718 (in Chinese with English abstract).

Zheng, Y. F. and Chen, J. F. (2000) Stable Isotope Geochemistry. Science Press, Beijing, 3-4 pp. (in Chinese).

Zhu, G. Y., Zhang, S. C. and Liang, Y. B. (2006) The characteristics of natural gas in Sichuan basin and its sources. Earth Sci. Front. 13, 234-248 (in Chinese with English abstract). 